\title{
Percepción de la calidad de vida en la vivienda. Periodo de contingencia por COVID-19 en la ciudad de Xalapa-México
}

\author{
Bertha Lilia Salazar Martínez ${ }^{1}$ | Luis Arturo Vázquez Honorato ${ }^{2}$ \\ Recibido: 16-06-2020 | en su versión final: 22-03-2021
}

Resumen

\begin{abstract}
Los cambios que el ser humano ha provocado en el medio ambiente generan deficiencias que desequilibran las condiciones de bienestar, colocando a la humanidad en posiciones divergentes al no proponer las respuestas adecuadas en cuanto al hábitat, el hogar y la calidad de vida del habitante, partiendo en un modelo de ciudad inequitativo y discriminante, que minimiza la respuesta integral colaborativa y fragmenta los derechos para obtener un hábitat insostenible. El período de la Contingencia COVID-19 en el contexto de México ha puesto en evidencia muchos problemas planteados en relación con propuestas inapropiadas, las cuales, estando en el encierro, ponen en discusión temas que impactan en el ser humano, como el medio ambiente, la economía, salud, etc. y en esencia una mezcla donde la estabilidad física y emocional del habitante es frágil. El objetivo de esta investigación es repensar la formulación de propuestas para producir un hábitat saludable, adecuado, equitativo y sostenible, que incentive la generación de ideas desde una visión sistémica integral, basada en una metodología cuantitativa para identificar situaciones relacionadas con la satisfacción en el hábitat, como caso de estudio se desarrolla en la ciudad de Xalapa, Veracruz. Los resultados muestran las condiciones reales de la vivienda, en las que se contrastaron las actividades con el espacio residencial, evidenciando las deficiencias reales en mantener a sus habitantes en una supuesta seguridad interna. Las conclusiones nos llevan a pensar la urgencia de nuevos enfoques sobre cómo mejorar la vivienda y dejar de pensar que el espacio público es el único satisfactor de las ausencias del sector privado, por lo que ofrecer alternativas integrales, diversas y flexibles es factible.
\end{abstract}

Palabras clave: Bienestar; habitabilidad; habitante; vivienda

Citación

Salazar, B. y Vázquez, L. (2021). Percepción de la calidad de vida en la vivienda. Periodo de contingencia por COVID-19 en la ciudad de Xalapa-México, ACE: Architecture, City and Environment, 16(46), 9492. DOI: http://dx.doi.org/10.5821/ace.16.46.9492

\section{Perception of the Quality of Life in the Dwelling. Contingency Period for COVID-19 in the City of Xalapa-Mexico}

Abstract

\begin{abstract}
The changes that the human being has caused in the environment generate deficiencies that unbalance the conditions of well-being, placing humanity in divergent positions by not proposing the appropriate responses regarding the habitat, the home, and the quality of life of the inhabitant, starting from in an inequitable and segregating city model, which minimizes the collaborative comprehensive response and fragments the rights to obtain an unsustainable habitat. The period of the COVID-19 Contingency in the context of México has made evident many problems raised in relation to inappropriate proposals, which, being in confinement, put into discussion issues that impact on the human being, such as the environment, the economy, health, etc. and in essence a mixture where the physical and emotional stability of the inhabitant is fragile. The objective of this research is to rethink the formulation of proposals to produce a healthy, adequate, equitable and sustainable habitat, which encourages the generation of ideas from a comprehensive systemic vision, based on a quantitative methodology to identify situations related to satisfaction in the habitat, as a case study it is developed in the city of Xalapa, Veracruz. The results show the real conditions of the house, in which the activities were contrasted with the residential space, evidencing the real deficiencies in keeping its inhabitants in supposed internal security. The conclusions lead us to think the urgency of new approaches on how to improve housing and stop thinking that public space is the only satisfactory of absences in the private sector, so offering comprehensive, diverse, and flexible alternatives is feasible.
\end{abstract}

Keywords: Well-being; habitability; inhabitant; dwelling

${ }^{1}$ Doctora en Arquitectura por la UNAM, Profesora de la Facultad de Arquitectura de la Universidad Veracruzana, México (ORCiD: 0000-0001-5575-1678, Scopus Author ID: 57210587805, WoS Researcher ID: AAR-9568-2021), ${ }^{2}$ Doctor en Arquitectura por la UNAM, Profesor de la Facultad de Arquitectura de la Universidad Veracruzana, México (ORCiD: 0000-0002-0622-561X, Scopus Author ID: 57210571167, WoS Researcher ID: AAR-9536-2021). Correo de contacto: Isalazar@uv.mx 


\section{Introducción}

Hasta hace unos meses no esperábamos que 2020 fuera un año tan devastador en todos los sentidos, por lo que resulta un hecho inédito lo que se está viviendo; ha sido un golpe a la sociedad que ha sacudido muchos sectores y ha puesto en evidencia las deficiencias existentes que desequilibran las condiciones de bienestar en el planeta, por lo que es necesario reconocer los errores, para que a partir de esa identificación se permita plantear una actitud esperanzadora con dirección hacia la justicia y la equidad, o como menciona Boltvinik (2020), hacia la construcción de un mundo diferente a los mundos anteriores.

Hace ya varios años se habían hecho advertencias sobre las consecuencias de los cambios que el ser humano ha provocado en el medioambiente a partir de la Revolución Industrial y sobre la priorización en la utilización de energías fósiles; que desde 1987 surge una preocupación real por "la gran aceleración" que enfatiza el consumo de los recursos primarios de una manera insostenible, la forma de la utilización de la energía y el crecimiento demográfico, que ahora repercute en este periodo denominado del Antropoceno, definición que lo relaciona con la posición central de las acciones del ser humano en el planeta (Issberner y Léner, 2018).

Esta situación genera tres vertientes, en primer lugar, desequilibrios en el medioambiente, con fenómenos naturales cada vez más violentos o condiciones como las que ahora vivimos con la generación de nuevos virus o bacterias potencialmente peligrosas para el ser humano. En segundo lugar, la exposición de la sociedad a diversos problemas vinculados a una visión minimalista de necesidades de suelo, vivienda, servicios elementales, movilidad, accesibilidad, la aparición de enfermedades nuevas o de desabasto, etc.; que han dejado a la humanidad en posiciones divergentes, al no contar con los recursos necesarios para resolver cada obstáculo que se presenta en un desarrollo social de desigualdad. Por último, los factores económicos inmersos en todas las naciones desde economías globales, que impactan en un incremento de las diferencias entre ricos y pobres, al no cumplir con las condiciones más elementales de sustentabilidad, medioambiente, sociedad y economía, desde una visión integral que culmina con la obtención de un hábitat insostenible.

Las vivencias actuales deben de servir de aprendizaje, para corregir todo aquello que se ha realizado con dinámicas equivocadas, se puede decir que el modelo de ciudad prevaleciente ha resultado inequitativo, segregador y no provee a sus habitantes de la mínima protección que se espera para una vida adecuada, por lo que se debe realizar un replanteamiento al modelo de ciudad, a partir del mejoramiento del hábitat en beneficio de todos sus habitantes, hacia un estado de bienestar y no solo de beneficio para aquellos que tienen los recursos.

A partir de la estrategia generalizada de control sanitario, definida a nivel mundial, se plantea una visión sobre las condiciones de la población para "quedarse en casa", ante el llamado de aplanar la curva epidemiológica, para evitar la propagación de la pandemia, bajo un enfoque en el que se cree que de esta forma pudiéramos relajarnos, leer, hacer ejercicio, regular nuestra relación con los demás miembros del hogar, al mejorar el tiempo de interacción familiar. Pero la realidad es tan diversa, que estas determinaciones debieran ser ligadas a una estrategia precisa de estudios sobre las características reales de la población en cada uno de nuestros lugares y en cada uno de los polígonos habitacionales, que establezcan las condiciones idóneas de actuación para contener los problemas que las acciones generan y no solo condenar a la población a tomar decisiones entre morir de hambre o morir de COVID-19. En la vivienda se ha hablado de muchos problemas en su constitución, pero ahora se ha hecho evidente la importancia de visualizarla inmersa dentro un sistema y no desde la visión del objeto de reclusión simple en el que, en el peor de los casos, su uso se limita a solo dormir. Esta "visibilización de las ausencias", nos permite recordar la concepción que desde 1986 Orlando Sepúlveda planteaba para la vivienda como un derecho fundamental reconocido desde 1948: "Es un

ACE, 16 (4.6) CC BY-ND 3.0 ES | UPC Barcelona, España | Percepción de la calidad de vida en la vivienda. Periodo 2 de contingencia por COVID-19 en la ciudad de Xalapa-México. DOI: http://dx.doi.org/10.5821/ace.16.46.9492 
lugar permanente y seguro que merece toda persona, para su resguardo y el de su familia, de recuperación física y emocional del trabajo diario y del que se sale cotidianamente rehabilitado para ganarse el sostén de los suyos y de sí mismo. Es un refugio familiar donde se obtiene comprensión, energía, aliento, optimismo para vivir y entregarse positivamente a la sociedad a la que se pertenece, una pequeña porción de territorio donde se reconoce exclusividad de uso." (Sepúlveda, 1986, p. 12)

Por lo que resulta importante evaluar la percepción de la calidad de vida ya que permite observar y analizar lo que siente la población, algo que desde 1994 la Organización Mundial de la Salud plantea como una preocupación de desarrollar este tipo de estudios bajo consideraciones de satisfacción con y desde el entorno en el que se habita (Nussbaum y Sen, 1998). Al asumir a la calidad de vida como "un concepto multidimensional y multidisciplinario que requiere valorarse desde condiciones materiales y espirituales que permitan el desarrollo psico-biológico y social-histórico del ser humano y la satisfacción personal con las condiciones de vida que cada persona ha logrado alcanzar" (Baldi y García 2005, p 9).

En concordancia con Iracheta (2020, p. 10) el panorama para el futuro debe "recuperar a los territorios para contar con una organización sólida con capacidad de articular las ciudades como parte de los objetivos regionales y nacionales de desarrollo económico, para la reducción de pobreza y la desigualdad".

\section{Desarrollo}

La vivienda debe ser vista más allá de un bien material, de comercialización o consumo, sino como un sistema dinámico de manifestación cultural, vinculante a su entorno, que define identidad y simbolismo, que evoluciona con el paso del tiempo y se somete a determinantes de crecimiento o disminución, transformación, declinación o extinción; en esencia un proceso continuo que requiere de la sociedad respuestas y soluciones integrales y dinámicas. Todo lo anterior, a partir del interés de articulación de los que participan en el proceso: su habitante individual o colectivo, como familia o agrupación social; los desarrolladores en sus aspectos de producción, financieros o de compraventa; los profesionales desde sus diversas disciplinas o enfoques; y el Estado con su aparato técnico, político y financiero en sus tres órdenes de gobierno, desde la interacción con su entorno físico y sus condiciones establecidas de consolidación en el polígono en el que se ubican.

En este proceso resulta fundamental la visualización del fenómeno habitacional como un sistema que articula particularidades desde sus factores cuantitativos y cualitativos, para la satisfacción completa de todas sus necesidades y motivaciones, como respuesta a actividades y funciones con sanidad y espaciamiento adecuado; consideraciones que deben de identificar la idiosincrasia y la cultura del habitante, para la satisfacción de las aspiraciones intelectuales, emocionales y espirituales. La amplitud de estos valores de análisis nos permite en primera instancia concebir la protección plena de sus derechos vinculantes e indivisibles para el buen desarrollo de los procesos de producción y gestión de la vivienda para la obtención del bienestar y la calidad de vida.

Desde nuestra referencia actual, uno de estos elementos de estudio que se han manifestado a partir del confinamiento es la pobreza de tiempo, normalmente se habla de la saturación de las actividades humanas en el espacio público y el tiempo se vinculaba con los procesos de movilidad, la realización de actividades laborales o domésticas en relación con el tiempo utilizado para la recreación, ocio o convivencia familiar, que pudiera darse en el exterior o el interior de la vivienda. A partir de esta situación se ha observado en gran medida la saturación del espacio de la vivienda, al limitar las posibilidades de realización de las actividades cotidianas, al permanecer todos sus habitantes en este espacio 24 horas y 7 días de la semana, se requiere de análisis de edades, nivel educativo, empleo,

ACE, 16 (46) CC BY-ND 3.0 ES | UPC Barcelona, España | Percepción de la calidad de vida en la vivienda. Periodo de contingencia por COVID-19 en la ciudad de Xalapa-México. DOI: http://dx.doi.org/10.5821/ace.16.46.9492 
estado de salud, características físicas y digitales del espacio en su interior y en su exterior. También han requerido de la capacidad adaptativa de sus habitantes para organizar, compartir y distribuir los tiempos y actividades necesarias, que han sido limitadas por las condiciones de las personas y las situaciones propias del entorno privado en el que habitan, afectando las condiciones de habitabilidad y de salud en la misma, dañando el bienestar, su ambiente e identidad.

Desde estas conceptualizaciones evidentes, al plantearse que cada día serán más cotidianas estas circunstancias, resulta necesario repensar la forma en la que son definidas las estrategias para los procesos de producción de vivienda nueva y de mejoramiento, determinados desde su calidad y no de su cantidad, desde su complejidad y no desde la simplicidad que evade; en la que se deben realizar estudios y proyectos de vivienda, definidos desde análisis profundos multidisciplinares, multisectoriales y multi-actorales, con enfoques desde la complejidad, la integralidad y el dinamismo ante la diversidad de evaluaciones, con planteamientos indivisibles, dimensionales, de características físicas, de escala, lugarización’, población, sanidad, políticas públicas, normativas, económicas o ambientales que requerirán de la construcción de un pensamiento de participación en la colaboración o de entretejer grupos para la producción de un hábitat adecuado (Haramoto, 2001).

Como punto de partida la imposibilidad de continuar generando propuestas relacionadas a un promedio o estándar, imposibilitando la cobertura a toda la población, considerándola solo para quienes pueden pagarla, dejando de lado, hasta el día de hoy, a una mayoría que no se ajusta a esas condiciones, sea por consideraciones de tenencia de la tierra, asequibilidad, número de personas, edad, situación económica, condiciones físicas del suelo, del espacio, de las personas, etc., cayendo en situaciones de especulación en sus diversas manifestaciones, pero siempre para el beneficio de unos cuantos.

Resulta frecuente, sobre todo en el otorgamiento de vivienda nueva, el que el adjudicado o beneficiado la considere incompleta ante sus expectativas, dejando en evidencia las deficiencias en la etapa de planeación del proyecto o desde la calidad constructiva de la obra, pero también suceden desde las ausencias del entorno, en el que el exterior de manera elemental, no otorga las condiciones para la realización de lo que se consideran necesidades de infraestructura básica o más allá, del equipamiento mínimo requerido que satisfaga sus necesidades de educación, salud, comercio, recreación o sociabilización y laborales.

Expectativas mínimas que deben cumplirse para el desarrollo de vivienda nueva o de mejoramiento y que ahora las circunstancias sanitarias nos han mostrado que ocurren en todas las viviendas, que su estudio no solo se base en su superficie justificada en la escasez de recursos económicos, por ello los procesos de colaboración social planteados pudieran impulsar la disminución económica en su ejecución y la satisfacción de la necesidades específicas para quienes habitan en las mayorías marginadas.

Así mismo, en las viviendas medias o residenciales, los procesos de producción vinculados con estudios integrales y de implementación colaborativa para la satisfacción de todos sus elementos de análisis, definirán un nuevo perfil de arquitecto, de talleres o despachos de arquitectura, cuyo significado no represente a aquel que desde un escritorio decide lo que considera viable para el proyecto y la familia a quien se le realiza la propuesta, si no vincula una visión multiescalar, multidisciplinar y multi-actoral en sus análisis y concibe el desarrollo de la arquitectura como un

\footnotetext{
1 Diversos autores (Sepúlveda, 1999; Jirón et al, 2004; González, 2004) han abordado la definición de lugarización como contrapartida a las tendencias de homogenización del entorno, sobre el privilegio a lo autóctono, lo vernáculo, lo natural y lo singular vinculado con el mundo y plenamente inserto en él, sobre la revalorización de la libertad, el pluralismo y la diversidad de infinidad de culturas locales conocidas, respetables y respetadas unas a otras, libres pero conectadas desde una infinidad de redes institucionales, económicas, culturales, políticas y de todo orden, en el que el espacio pasa a convertirse en lugar, pues es observado y delimitado, adquiriendo una significación social.
}

ACE, 16 (46) CC BY-ND 3.0 ES | UPC Barcelona, España | Percepción de la calidad de vida en la vivienda. Periodo de contingencia por COVID-19 en la ciudad de Xalapa-México. DOI: http://dx.doi.org/10.5821/ace.16.46.9492 
proceso y no como un objeto, con fundamento en el diálogo de saberes. Como referencia hacia estos estudios daremos pie a algunos de estos análisis, reconociendo la diversidad que pudiera darse a partir de los diferentes enfoques existentes y la variabilidad de las circunstancias que los generan, para contribuir con una visión integral del sistema habitacional.

Desde la pauta de lo que Bachelard (2000, p. 251) menciona "es preciso reflexionar para medir, antes que medir para reflexionar", lo que nos define el fundamento de lo planteado en esta investigación, con la intención de determinar los elementos demostrativos que aportan a la construcción de una nueva visión para la producción de un sistema habitacional adecuado, equitativo, saludable y sustentable.

\subsection{Medioambiente/calidad de vida}

Se ha visto en este periodo que al detener la actividad productiva del hombre se empieza a dar indicios de que la naturaleza se consigue estabilizar, por lo que se puede pensar que si el consumo humano es responsable, por debajo de la línea "de remplazo", pudieran repararse las condiciones ambientales del planeta, esto es una esperanza para la humanidad para encontrar soluciones al mejoramiento del hábitat y, en el caso de "hacer ciudad", detener el impacto ambiental y la pérdida de biodiversidad cuando se realizan ciudades extensas y menos densas. Según datos de la ONU (2020) la actividad humana ha alterado el $75 \%$ de la superficie terrestre por lo que la naturaleza queda en una pequeña porción del planeta, por lo que "Cualquier impacto ambiental positivo después de esta aborrecible pandemia debe comenzar por el cambio en nuestros hábitos de producción y consumo hacia modelos más limpios y sostenibles" (ONU, 2020).

Si no vemos a la naturaleza en el mismo nivel, "la salud de las personas y la salud del planeta son una y la misma cosa y ambas pueden prosperar de igual medida" (ONU, 2020), lo que puede suceder es que no exista punto de retorno y cada vez sean fenómenos más intensos para los que no estemos preparados.

Cuando la lógica del capital se mueve en una dirección desvinculada de la producción de la vida, de existencia de los sujetos, ecosistemas y de su reproducción, va cerrando la energía social, para encausarse solo en la multiplicación de objetos y su producción, en detrimento de la relación naturaleza-sociedad, que generó la división entre ciudad-campo e inició una fractura ecológica hasta nuestros días.

Pero como cuestiona desde la salud Breilh (2010, p. 86), “¿hay realmente espacio para la vida en un sistema social centrado en la búsqueda frenética de la ganancia y la productividad?, ¿En el modelo urbano tiene vigencia el derecho a la salud?”, o será que la codicia está silenciando la lógica y los lenguajes en detrimento del ser humano y la capacidad de la madre naturaleza para cobijar la vida. Por lo que se plantea desde la relación humana y el ecosistema, el vínculo entre espacio, geografía urbana y ecología urbana, actualmente denominado ecosistema urbano, como una relación que vea más allá de las restricciones que impone la teoría del espacio urbano y las conceptualizaciones que minimizan la salud y el ambiente y permite adentrarse en un planteamiento integral, que para Lefebvre (2001) se concebía desde la reconciliación entre el espacio mental y el espacio real, físico y social en el que habitamos.

Es necesario reconocer que la salud urbana se observa desde una perspectiva del movimiento entre sujetos y objetos, como un espacio dinámico, complejo y de movimiento creador, que vincula lo biológico desde un nexo interno en el que existe un cambio permanente del patrón de transformaciones mutuas que se establecen entre los habitantes y el ambiente, y en el que incide jerárquicamente lo social.

ACE, 16 (46) CC BY-ND 3.0 ES | UPC Barcelona, España | Percepción de la calidad de vida en la vivienda. Periodo de contingencia por COVID-19 en la ciudad de Xalapa-México. DOI: http://dx.doi.org/10.5821/ace.16.46.9492 
En concordancia con Ezquiaga (2020), una de las ventajas de las ciudades donde puede albergar la proximidad de muchas personas, deviene en vulnerabilidad y la densidad se percibe como un factor de riesgo para la salud de los habitantes.

Es vital proteger este fundamento dialéctico, como menciona Breilh (2010), para que no se incline en el determinismo biológico, ni en el determinismo histórico, al estimular las relaciones socialbiológicas y de sociedad-naturaleza, dado que la historia de la naturaleza y la historia de los seres humanos se deben condicionar recíprocamente, para no perder su existencia. Es ahí donde se ha fallado, ya que los condicionamientos entre el desarrollo natural y la permanencia de las actividades de los seres humanos se han desbalanceado y el mayor peso se ha inclinado hacia la supremacía humana, sin comprender los diagnósticos de las formas de vida, que explican los patrones de reacción y las vulnerabilidades que estas condiciones generan.

En el sistema habitacional es donde el habitante, la familia y la colectividad determinan sus estilos de vida, definidos desde sus procesos fisiológicos, de soportes y de defensas físicas y psicológicas, fisiopatológicas, de vulnerabilidades o debilidades psicológicas, que dan muestra de manera positiva o negativa las relaciones que se tienen con el espacio, que varían según la clase social y las características del contexto en el que se insertan y desde el cual debiera iniciar la recuperación ecológica, que se manifiesta con la restauración de la sociedad con la naturaleza. Ezquiaga (2020) menciona que se han evidenciado graves contradicciones en la gestión urbana actual, como la inequidad en el acceso a los bienes públicos, la dimensión insuficiente o el diseño inadecuado del espacio. Es importante integrar temas de relevancia social en las propuestas del entorno construido actual, tal como hace referencia Biere (2021) como herramienta de análisis "Retos y paradigmas de la ciudad contemporánea”.

\subsection{Economía/calidad de vida}

En las declaraciones de Thomas Piketty, expuestas en la entrevista proporcionada a Spinney (2020), comenta que "La pandemia actual podría acelerar la transición hacia otro modelo económico, hacia una organización más equitativa, más sustentable, de nuestro sistema económico internacional”, por lo que, al plantear esta transformación, todos los ámbitos deberían también verse obligados a cambiar, como es el caso de la ciudad. Se tendría que repensar su economía, servicios, instalaciones y por ende también debería existir alternativas diferentes de vivienda, no el prototipo de vivienda impuesto en todas las regiones del planeta por un modelo neoliberal, donde se ha visto privilegiado el mercado inmobiliario y los usuarios son los menos afortunados con los modelos existentes, ya que se apostó a una tipología que no ofrece nada a los habitantes.

La pandemia pone en juego no solo los bienes, sino la calidad de los bienes, ya que las viviendas no pueden enfrentar de una manera adecuada situaciones como las actuales (Ziccardi, 2020), debido a que prevaleció el énfasis al diseño y desarrollo del espacio público y la realidad actual refleja que no es posible utilizarlo. Piketty afirma que existen muchas naciones que aseguran que no podemos regresar al modelo económico anterior y considera que debe existir un cambio después de esta situación, pero aún es difícil saber cuál predominará (Spinney, 2020), lo que se desea es que la situación económica internacional no afecte aún más la calidad de vida de todos.

La estela que esta enfermedad ha dejado tiene que ver con la incompatibilidad para una gran mayoría entre trabajar y proteger la salud, que tras la estrategia de "Quédate en casa" se les ha limitado la posibilidad de salir a realizar sus actividades laborales, pero no se les ha dicho el con qué recursos podrán comprar sus alimentos, otros bienes y servicios esenciales.

ACE, 16 (46) CC BY-ND 3.0 ES | UPC Barcelona, España | Percepción de la calidad de vida en la vivienda. Periodo de contingencia por COVID-19 en la ciudad de Xalapa-México. DOI: http://dx.doi.org/10.5821/ace.16.46.9492 
Los habitantes pobres de México y del mundo cuyas posibilidades de ahorro han sido nulas han seguido en la búsqueda de continuar trabajando para sobrevivir, arriesgando su salud y las de sus familiares. Estas circunstancias han puesto sobre la mesa la posibilidad de vincular al Estado nuevamente, a una nueva vertiente del Estado benefactor, aportando lo que Julio Boltvinik (2020), denomina el "Ingreso Ciudadano Universal Suficiente e Incondicional" (ICUSI) en nuestro país. Con esto se evitaría arriesgar la vida de estos ciudadanos para la obtención del pan diario. En México surgieron financiamientos de bajo interés en apoyo a las pequeñas y microempresas y algunas transferencias monetarias de programas sociales para disminuir la caída de los ingresos, siendo insuficientes para la contención de la crisis.

Situación que muchos de los países pretenden enfrentarla a partir de gravar temporalmente a los ricos, como menciona Piketty, esta estrategia fue realizada después de la segunda guerra mundial por países como Alemania y Japón, iniciando su reconstrucción cinco años después del final de la guerra sin ninguna deuda pública (Spinney, 2020).

Por otra parte, también resulta necesario el incentivo hacia el establecimiento de cadenas de producción locales o regionales que busquen restablecer la economía y la generación de espacios de articulación entre productores y consumidores a pequeña escala, que generan redes de producción regionales e impulsen la economía desde lo local en beneficio de la calidad de vida.

\subsection{Sociedad, salud, pobreza de tiempo/calidad de vida}

De no tomarse en cuenta los elementos que pueden proporcionar a la sociedad un estado de confort colectivo, se corre el riesgo que menciona Byung-Chul Han en las afirmaciones proporcionadas en entrevista a Sigüenza (2020), "La histeria por la supervivencia, hará que la sociedad sea más inhumana", "Sobrevivir se convertirá en algo absoluto" (Sigüenza, 2020).

Los sectores más humildes están más expuestos a este tipo de crisis, desde el hecho que no pueden permanecer en casa, porque no la tienen, porque su trabajo y estabilidad económica depende de salir de ella, en el caso de tenerla, con dimensiones de $30 \mathrm{~m}^{2}$ donde no hay iluminación ni ventilación natural y existe hacinamiento (Vargas, 2020), pero también a las clases medias se le están rebasando las situaciones por estar confinados, en ambos casos se observa disminución en la calidad de vida. ONU-hábitat estima que al menos el 38.4\% de la población de México habita en una vivienda no adecuada, es decir, en condiciones de hacinamiento, hecha con materiales no duraderos o que carece de servicios de agua y saneamiento (ONU Hábitat, 2018). Esto representa que, de una población de 128,000,000 habitantes (INEGI, 2020), unos 49,150,000 se encontraban en estas condiciones de hacinamiento.

La diferencia entre Europa y Latinoamérica del "Quédate en casa" refleja que la pandemia no solo es un problema sanitario, sino social, se resaltan las diferencias sociales y queda evidente que vivimos en una sociedad de dos clases, debido a que no todos tienen el "privilegio de tener una vivienda", "Quédate en casa" es solo para quienes la tienen, y la segunda situación que se presenta es que aun cuando la tengas se debe pensar en qué condiciones está para recibir a sus habitantes las 24 horas, durante los 7 días de la semana. En ese sentido, los resultados de permanecer en el confinamiento de la vivienda o al interior de esta no solo se relacionan con estar de la puerta hacia adentro, debido a que la diversidad en las maneras de vivir se vincula con formas diferenciadas de vivienda en México y muestran muchos problemas con las viviendas en hacinamiento (Romero, 2020). Esto también se relaciona con una consideración de construcción de políticas públicas adecuadas a las características reales de población en México, determinadas desde la diversidad de características de la población con un enfoque integral, que permita la creación de condiciones de apoyo diferenciadas a la medida de quien la recibe.

ACE, 16 (4.6) CC BY-ND 3.0 ES | UPC Barcelona, España | Percepción de la calidad de vida en la vivienda. Periodo de contingencia por COVID-19 en la ciudad de Xalapa-México. DOI: http://dx.doi.org/10.5821/ace.16.46.9492 
Por ejemplo, la renta tiene que ver mucho con la seguridad de permanencia, sobre todo para la no existencia de desalojos en los grupos que tienen carencias. Existe una gran cantidad de renta en colonias populares en México, que ante estas condiciones se encuentran en alto riesgo de ser desalojadas, ante la imposibilidad del pago; pero en algunos casos, puede ser peor estar todos adentro de la vivienda debido a la cantidad de habitantes que en ella residen y en caso de enfermedad la propagación de contagios es mayor para todos. Con la finalidad de compartir recursos, las acciones humanas se vinculaban con el desarrollo y cuidado de la vida, a partir del cuidado al intercambio de lo material específico, ecológico y lo social, desde las relaciones, las necesidades y las capacidades de los individuos, para vivir y convivir entre ellos y con su entorno. Empero, ya se ha mencionado que un sistema económico actual, constituido por la acumulación del capital que genera una sociedad mercantilista, no vincula su sistema de producción para beneficio de la conservación de la vida e incrementa la destrucción del entorno y sus recursos, aumenta la pobreza y la desigualdad e incentiva el desarrollo de enfermedades físicas y psicológicas para todos los seres vivos.

En principio la fragmentación entre la ciudad y el campo da comienzo a la fractura ecológica, pérdida de energía social y bases naturales para el sustento de la vida, denunciada desde el siglo XIX (Anderson, 2004) por la economía política, impidiendo conservar los recursos para beneficio de la cadena de las generaciones humanas. Hasta la construcción de grandes ciudades de economía global, en la que impera la irracionalidad del modelo, por una conformación espacial deficiente y ecológicamente no sustentable, que genera degradación, depredación y contaminación, con el incremento en daños en la salud de quienes la habitan.

Según datos proporcionados por la ONU el 75\% de las nuevas enfermedades infecciosas son transmitidas de animales a humanos debido a la fragilidad de los ecosistemas, por extraer a los animales de su entorno y la cercanía con los seres humanos, se enfatiza con el cambio climático al favorecer la resistencia antimicrobiana; son factores que incentivan el que incremente la probabilidad de contagios para los seres humanos (ONU, 2020). Pero la posibilidad para el buen vivir y la obtención de modos de vida saludables no debe ser reducida a estudios que culminan siendo expiatorios de expresiones de carencia o pérdidas físicas, que no culminan en procesos de fondo, por lo que se requiere considerar nuevos criterios desde las tres dimensiones condicionantes y garantías para la generación espacial:

- "General: Capacidad sustentable, derechos económicos y sociales, derechos de la naturaleza;

- Particular: Modos de vida saludables, protegidos, con soportes colectivos, con identidad propia y dignificantes, en ambientes saludables;

- Singular: Acceso a trabajo digno, consumo pleno y empoderado, y ecosistemas domésticos saludables" (Breilh, 2010, p. 92).

El estar dentro de la vivienda tiene muchas modalidades, que van desde la ubicación y la tipología específica, desde los que tienen solo el pasillo de acceso y la vivienda pequeña, a quienes tiene patios, jardines, en los conjuntos habitacionales que tienen andadores y espacio de convivencia.

En muchas ocasiones se piensa que la pobreza se relaciona con cuestiones económicas, pero a través de los años se ha visto que la población también carece de otros elementos importantes para su calidad de vida.

El tiempo como un recurso esencial para la satisfacción de necesidades. "El tiempo es un recurso fundamental de los hogares y su disponibilidad (o su carencia) afecta directamente la calidad de vida" (Damián, 2005, p. 807). Se tiene evidencia que existen numerosos trabajos que han estudiado al tiempo desde diversas perspectivas, muy pocos lo han vinculado al análisis de la pobreza.

ACE, 16 (4.6) CC BY-ND 3.0 ES | UPC Barcelona, España | Percepción de la calidad de vida en la vivienda. Periodo de contingencia por COVID-19 en la ciudad de Xalapa-México. DOI: http://dx.doi.org/10.5821/ace.16.46.9492 
Desde 1995, Constance Citro y Robert T. Michael mencionaron que pueden existir familias en las mismas condiciones económicas, pero pueden tener diferencias en la distribución de los tiempos, lo que debería ser tomado en cuenta para definir su bienestar, derivado de esto, Araceli Damián hace una reflexión de los tiempos que se requieren, no solo el de trabajo, sino también el de traslado de la casa a los lugares productivos y educativos, el tiempo para la casa, la tenencia de aparatos eléctricos que reducen el tiempo de trabajo doméstico, y el tiempo de ocio, como visitar a amigos o familiares, celebraciones, asistir a las escuelas de los hijos en días especiales, tener un pasatiempo o poder realizar alguna actividad recreativa o deportiva. Damián menciona que existen tres tipos de satisfactores para favorecer los menesteres humanos: los objetos (ya sean bienes o servicios), las relaciones y las actividades (Damián, 2005). Con la situación actual la calidad del tiempo de convivencia se ha visto disminuido debido al teletrabajo, o con hijos en edad escolar, el realizar sus actividades académicas requieren más tiempo de visualización de pantalla electrónica, el abasto de alimentos se ha vuelto tedioso, por las medidas sanitarias establecidas para evitar contagio y el incremento del trabajo doméstico, ya que en el mejor de los casos las viviendas cuentan con espacios para poder realizar actividades físicas (deportivas o lúdicas). Además de lo anterior, en concordancia con datos de la ONU, una vivienda adecuada debe contar con los siguientes aspectos para que los habitantes puedan disfrutar del lugar con buena calidad de vida.

Siete elementos de la vivienda adecuada:

- $\quad$ "Seguridad de tenencia: que los habitantes estén protegidos contra desalojo, hostigamiento y otras amenazas.

- $\quad$ Disponibilidad de servicios materiales, equipamiento e infraestructura: es decir, acceso al agua potable, instalaciones sanitarias adecuadas, energía para cocción y conservación de alimentos.

- Asequibilidad: el costo de la vivienda debe hacer que los habitantes puedan acceder a ella sin poner en riesgo los otros satisfactores de la vivienda que constituyen una vida digna, la educación o a la salud.

- Habitabilidad: no solo servicios urbanos, el acceso que pueden tener ciertos grupos etarios para movilidad, alimentos, etc., se ve agravado si las viviendas no cuentan con servicios, la vivienda debe garantizar la seguridad física y psicológica de los habitantes.

- Accesibilidad: que el diseño sea libre de barreras arquitectónicas, para que los habitantes de todas las edades puedan disfrutar del entorno.

- Ubicación: debe ofrecer acceso a oportunidades de empleo, servicios, salud, escuelas.

- Adecuación cultural: dotación de vivienda que debe ser propia de la cultura del lugar, tomar en cuenta la identidad cultural de los usuarios" (ONU-Hábitat, 2018, p. 53).

Como reflexión, antes de la pandemia se tenía pobreza de tiempo por el recorrido de la casa al trabajo o a las actividades fuera de ella. Actualmente, con la pandemia, se generó pobreza de tiempo por tratar de resolver todas las actividades al interior de la vivienda, sin que esta estuviera lista 0 preparada para ello.

\section{Metodología}

Para el caso particular de esta investigación de tipo cuantitativa, se utilizó como instrumento una encuesta de veintisiete preguntas a 156 personas los días 14 al 21 de mayo de 2020, con la finalidad de saber su opinión sobre la respuesta que su vivienda ha ofrecido para la realización de sus actividades diarias, después de 55 días de que fuera decretada la medida "Quédate en casa", a partir del 20 de marzo del mismo año, propuesta por el Gobierno de México, a través de la Secretaría de Salud (Gobierno de México, 2020).

ACE, 16 (46) CC BY-ND 3.0 ES | UPC Barcelona, España | Percepción de la calidad de vida en la vivienda. Periodo de contingencia por COVID-19 en la ciudad de Xalapa-México. DOI: http://dx.doi.org/10.5821/ace.16.46.9492 
La encuesta se basó en considerar actitudes y conocer en cierta medida el grado de conformidad o satisfacción de los encuestados sobre su percepción del bienestar que su vivienda les ha ofrecido en función de las actividades que pueden realizar al interior de ellas, ante este fenómeno "Quédate en casa”, derivado de la contingencia COVID-19 a partir de la utilización de una escala de medición de Likert en 27 preguntas definidas en elementos demostrativos de análisis sobre 1. Actividades ambientales, 2. Actividades económicas, 3. Actividades educativas o laborales, 4. Actividades sociofuncionales, 5. Actividades de salud y 6. Actividades sobre tiempo libre.

Se utilizó la plataforma digital Google Forms para una encuesta virtual, a ser aplicada a estudiantes, profesores y sus familiares, de la Facultad de Arquitectura de Xalapa, de la Universidad Veracruzana, México, tomando en consideración sus tres niveles de enseñanza, Doctorado, Maestría y Licenciatura; para identificar la percepción que tienen sobre la vivienda en tiempo de confinamiento.

Xalapa es la Capital del Estado de Veracruz, México, se caracteriza por ser una ciudad que su economía se sustenta en servicios y en actividades correspondientes al sector educativo, su Universidad Veracruzana se conforma de una infraestructura que congrega a una gran población, que sustenta a esta Universidad Pública Estatal.

\subsection{Muestra}

Se aplicó a 156 personas relacionadas con la Facultad de Arquitectura Xalapa, a partir de una selección de estudiantes de experiencias educativas vinculadas con profesores del Cuerpo académico Cultura del Hábitat, con la idea de un manejo de conocimientos sobre satisfacción y necesidad o deficiencias en la vivienda previamente estudiados, en los diferentes niveles del mapa curricular de los programas de Licenciatura, Maestría y Doctorado, considerando a los familiares de estos, con edades diversas de 4 a 78 años, de acuerdo con el tipo de habitantes que hacen uso de la vivienda. Cabe mencionar que a los más pequeños se les asistió con la lectura de la encuesta.

\subsection{Herramienta}

La recolección de datos se realizó mediante la aplicación de una encuesta de percepción de la vivienda, en la plataforma virtual Google Forms, con 27 preguntas relacionadas sobre las actividades que se realizan durante el periodo de contingencia COVID-19, a partir de una escala de medición de Likert para cada una de las preguntas. En la captura de la base de datos se utilizó Office 2010 con el software Excel, y la presentación de resultados se definió a partir de gráficas.

\subsection{Instrumento de evaluación}

La encuesta se desarrolla con base en análisis estadísticos y sus ítems se responden a través de la escala de Likert. Con las 27 preguntas se pretende conocer la percepción de la habitabilidad en el interior de la vivienda en tiempo de confinamiento de los estudiantes y profesores de la Facultad de Arquitectura Xalapa, así como de sus familiares.

La encuesta se dividió según elementos demostrativos relacionados en 6 tipos de actividades realizables al interior de la vivienda: 1) 11 ítems se relacionaban sobre conocer la percepción de actividades socio-funcionales; 2) 9 ítems sobre actividades de salud; 3) 4 ítems sobre consideraciones ambientales; 4) 3 ítems se relacionaban sobre actividades educativas; 5) 3 ítems sobre actividades de pobreza de tiempo y, por último, 6) 2 ítems sobre actividades económicas.

ACE, 16 (46) CC BY-ND 3.0 ES | UPC Barcelona, España | Percepción de la calidad de vida en la vivienda. Periodo de contingencia por COVID-19 en la ciudad de Xalapa-México. DOI: http://dx.doi.org/10.5821/ace.16.46.9492 


\subsection{Limitantes}

Al ser realizada esta encuesta durante la implementación de la medida general, instaurada por el Gobierno de México "Quédate en casa", fue aplicada a través de medios virtuales, con recursos limitados, acotada a estudiantes y profesores de la Facultad de Arquitectura Xalapa; así como de sus familiares que habitan en la ciudad de Xalapa, Veracruz, permitir conocer la opinión de una población que se relaciona con la creación de espacios habitables y de sus familiares, desde la percepción de la efectividad en la relación vivienda/actividad, que al ser una Capital Estatal, cuya actividad productiva se genera en mayor porcentaje en servicios públicos y de educación, resulta relevante la relación hacia una gran cantidad de población.

\section{Diagnóstico y análisis de resultados}

La ciudad de Xalapa se encuentra ubicada en el municipio del mismo nombre, en la Región Capital del estado de Veracruz. Rodeada por 6 municipios (al norte Banderilla y Jilotepec, al este Rafael Lucio, al sur Emiliano Zapata y Coatepec, al oeste San Andrés Tlanelhuayocan), además de incorporar a dos municipios cercanos, Xico y Cosautlán, para conformar la Zona Metropolitana de Xalapa, que para el 2018 tenía 795,281 habitantes (INEGI, 2018).

Se caracteriza por albergar los tres poderes de Gobierno del Estado, además de dotar de un fuerte impulso hacia el sector educativo ya que se encuentran concentradas en sus límites varias Universidades, así como escuelas desde el nivel básico hasta el medio superior. Por estos motivos es de interés realizar el estudio, debido a que Xalapa tiene como actividad económica principal el de ofrecer servicios.

A continuación, se muestra algunas de las preguntas elaboradas y las respuestas que dieron los habitantes encuestados a través de gráficas que se elaboraron a partir de este grupo datos en concordancia con la estructura del desarrollo de este documento.

- Medioambiente / calidad de vida

- Economía / calidad de vida

- $\quad$ Sociedad, salud, pobreza de tiempo/calidad de vida y la valoración de la vivienda

En la Tabla 1 se detallan los resultados relacionados con las preguntas referentes a medioambiente y calidad de vida, donde se hace evidente la necesidad de los habitantes del contacto con la naturaleza y las condiciones actuales de las viviendas no hacen posible este vínculo.

En la Tabla 2 se muestran los resultados relacionados con las preguntas referentes a economía y calidad de vida, donde se hace evidente la necesidad de los habitantes de seguir con las actividades que permitan a los integrantes de la familia tener un sustento, también se observa que las viviendas en las condiciones actuales no permiten la diversidad de actividades debido al diseño inadecuado de los espacios.

En la Tabla 3 se señalan los resultados relacionados con las preguntas referentes a sociedad, salud, pobreza de tiempo y calidad de vida, donde se hace evidente las condiciones espaciales deficientes de la vivienda que no permiten desarrollar adecuadamente las actividades básicas para cualquier ser humano.

ACE, 16 (4.6) CC BY-ND 3.0 ES | UPC Barcelona, España | Percepción de la calidad de vida en la vivienda. Periodo de contingencia por COVID-19 en la ciudad de Xalapa-México. DOI: http://dx.doi.org/10.5821/ace.16.46.9492 
Tabla 1. Medioambiente / calidad de vida

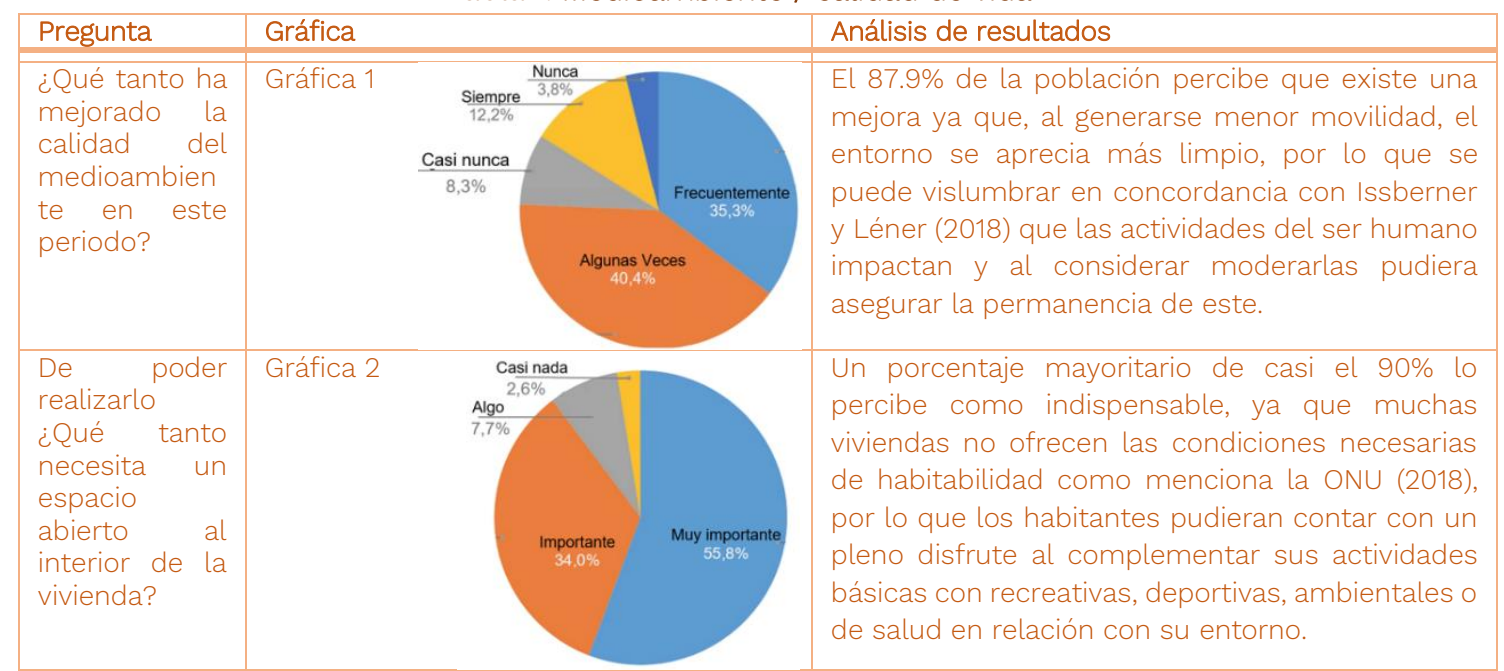

Fuente: Elaboración propia

Tabla 2. Economía / calidad de vida

\begin{tabular}{|c|c|c|}
\hline Pregunta & Gráfica & Análisis de resultados \\
\hline $\begin{array}{l}\text { Durante este } \\
\text { periodo de } \\
\text { confinamiento } \\
\text { ¿tuvo que salir } \\
\text { de su vivienda } \\
\text { por causa de } \\
\text { trabajo o } \\
\text { actividades } \\
\text { económicas? }\end{array}$ & $\begin{array}{r}\text { Gráfica } 3 \\
\\
\begin{array}{r}\text { Nunca } \\
1,9 \%\end{array}\end{array}$ & $\begin{array}{l}\text { Se muestra como resultado que el } 50.7 \% \text { de los } \\
\text { habitantes ha tenido que salir de su vivienda, el } 49.5 \% \\
\text { menciona que algunas veces o nunca, esto refleja la } \\
\text { situación en la ciudad de Xalapa, que como ya se había } \\
\text { señalado con anterioridad la actividad productiva a la que } \\
\text { se dedica la población es de servicios o pertenece al } \\
\text { sector educativo, el } 25 \% \text { de los encuestados menciona } \\
\text { que aun así salió por distintos motivos, aunque solo un } \\
12 \% \text { de los encuestados declararon que permanecieron } \\
\text { en total aislamiento, las respuestas reflejan que a pesar } \\
\text { de las condiciones un número importante si tuvo } \\
\text { necesidad de salir. }\end{array}$ \\
\hline $\begin{array}{l}\text { ¿Ha podido } \\
\text { realizar sus } \\
\text { actividades } \\
\text { laborales o en } \\
\text { el caso de } \\
\text { estar } \\
\text { estudiando } \\
\text { educativas en } \\
\text { su vivienda? }\end{array}$ & $\begin{array}{l}\text { Más de } 8 \\
22,4 \%\end{array}$ & $\begin{array}{l}\text { Se refleja que el } 55.7 \% \text { de los encuestados se encuentran } \\
\text { en una vivienda que les ha permitido desarrollar las } \\
\text { actividades de trabajo en casa o recibir educación en línea } \\
\text { con jornadas prolongadas de más de } 8 \text { hrs. El } 25 \% \text { tuvo } \\
\text { dificultades al realizarlas y destinó pocas horas a dicha } \\
\text { actividad, lo que se deduce que casi el } 30 \% \text { de las } \\
\text { viviendas no tienen los espacios necesarios para poder } \\
\text { desarrollar las actividades laborales o educativas, cuyas } \\
\text { razones pueden ser por distintas causas, por falta de un } \\
\text { espacio adecuado que permita trabajar en condiciones } \\
\text { ideales y sin la distracción que genera la familia o también } \\
\text { puede ser por el cruce de horarios entre el número de } \\
\text { miembros de la familia, ya que al llevar el trabajo y/o la } \\
\text { escuela a casa, las actividades se sobrepusieron, lo que } \\
\text { originó la necesidad de una organización o priorización de } \\
\text { actividades por habitante, según las decisiones de cada } \\
\text { una de estas familias, que culminó en el caso más } \\
\text { desfavorable con la consideración de pobreza de tiempo } \\
\text { y disminución de la calidad de vida de sus miembros, en } \\
\text { concordancia con el estudio expuesto de Damián (2005). }\end{array}$ \\
\hline
\end{tabular}

Fuente: Elaboración propia.

ACE, 16 (4.6) CC BY-ND 3.0 ES | UPC Barcelona, España | Percepción de la calidad de vida en la vivienda. Periodo de contingencia por COVID-19 en la ciudad de Xalapa-México. DOI: http://dx.doi.org/10.5821/ace.16.46.9492 
Tabla 3. Sociedad, salud, pobreza de tiempo / calidad de vida

\begin{tabular}{|c|c|c|}
\hline Pregunta & Gráfica & Análisis de resultados \\
\hline $\begin{array}{l}\text { ¿Ha } \\
\text { presentado } \\
\text { estrés o } \\
\text { ansiedad por } \\
\text { el } \\
\text { confinamiento } \\
\text { en este } \\
\text { periodo } \\
\text { contingencia } \\
\text { CovID-19? }\end{array}$ & $\begin{array}{l}\text { Gráfica } 5 \\
\qquad \begin{array}{cc}\text { Nunca } \\
\text { Casi } \\
\text { Nunca } \\
12,8 \% \\
\text { Frecuentemente } \\
27,6 \% & \text { Siempre } \\
\text { Algunas veces } & \\
42,3 \%\end{array} \\
\end{array}$ & $\begin{array}{l}\text { El 39.1\% de la población presentó ansiedad o estrés } \\
\text { con frecuencia, otro } 42.3 \% \text { algunas veces, lo que } \\
\text { quiere decir que la salud ha sido afectada al no } \\
\text { estar preparados con condiciones adecuadas en la } \\
\text { vivienda para establecer una organización espacial } \\
\text { y desarrollo de actividades de todos sus miembros } \\
\text { durante las } 24 \text { horas y los } 7 \text { días de la semana que } \\
\text { el confinamiento generó, tal como lo expresó } \\
\text { Byung-Chul Han (Sigüenza, } 2020 \text { ), donde lo } \\
\text { peligroso de este escenario es que se pueda llegar } \\
\text { a situaciones más violentas, vulnerando a los } \\
\text { habitantes e incrementando los índices de violencia } \\
\text { familiar. }\end{array}$ \\
\hline $\begin{array}{l}\text { Durante este } \\
\text { periodo de } \\
\text { confinamiento } \\
\text { ¿Ha podido } \\
\text { descansar lo } \\
\text { suficiente en } \\
\text { su vivienda }\end{array}$ & $\begin{array}{l}\text { Gráfica } 6 \\
\qquad \begin{array}{c}\text { Nunca } \\
\text { Siempre } \\
9,0 \% \quad \text { Casi } \\
\text { Nunca } \\
10,3 \% \\
\text { Frecuentemente } 45,5 \% \\
33,3 \%\end{array} \\
\text { Algunas veces } \\
\end{array}$ & $\begin{array}{l}\text { Se puede determinar que un } 42.3 \% \text { de los } \\
\text { habitantes han podido descansar, pero de igual } \\
\text { forma un } 45.5 \% \text { menciona que en un rango de } \\
\text { algunas veces a nunca han descansado, es un dato } \\
\text { que debe tomarse en cuenta, debido a que en } \\
\text { concordancia con J. vargas (2020), las condiciones } \\
\text { de los espacios o la saturación de los mismos por } \\
\text { la permanencia de } 24 \text { horas durante los } 7 \text { días de la } \\
\text { semana, no permiten a los habitantes realizar con } \\
\text { plenitud sus actividades, disminuyendo su calidad } \\
\text { de vida, al modificar la manera en las que se } \\
\text { realizan las actividades cotidianas (Sepúlveda, 1986) } \\
\text { e impactando en las condiciones de estrés, } \\
\text { mencionadas en la pregunta anterior. }\end{array}$ \\
\hline $\begin{array}{l}\text { Durante este } \\
\text { periodo de } \\
\text { confinamiento } \\
\text { ¿Ha podido } \\
\text { realizar } \\
\text { actividades } \\
\text { físicas o } \\
\text { deportivas? }\end{array}$ & $\begin{array}{l}\text { Gráfica } 7 \\
\qquad \begin{array}{c}\text { Siempre } \\
\text { Casi } \\
\text { Nunca } \\
23,7 \% \\
\text { Algunas veces } \\
25,0 \%\end{array}\end{array}$ & $\begin{array}{l}\text { Se evidencia que solo un } 32.1 \% \text { de estos habitantes } \\
\text { han podido realizar actividades físicas (deportivas o } \\
\text { de activación); pero un } 68 \% \text {, en un rango de algunas } \\
\text { veces a nunca, menciona que no ha podido realizar } \\
\text { las actividades, es un dato que debe tomarse en } \\
\text { cuenta, debido a que en concordancia con Ziccardi } \\
\text { (2020) y ONU (2018), ya que las condiciones de los } \\
\text { espacios al interior de la vivienda no permiten a las } \\
\text { personas realizar con plenitud sus actividades, } \\
\text { debido a que se dio énfasis al desarrollo de los } \\
\text { espacios públicos, dejando sin atender los espacios } \\
\text { de esparcimiento al interior de la vivienda } \\
\text { disminuyendo las condiciones de habitabilidad de la } \\
\text { misma. }\end{array}$ \\
\hline $\begin{array}{l}\text { Durante este } \\
\text { periodo de } \\
\text { confinamiento } \\
\text { ¿Ha tenido } \\
\text { problemas de } \\
\text { actividades } \\
\text { simultáneas } \\
\text { propias o con } \\
\text { actividades } \\
\text { familiares? }\end{array}$ & $\begin{array}{l}\text { Gráfica } 8 \\
\text { Casi nunca } \\
9,6 \% \\
\text { Siempre } \\
11,5 \% \quad \text { Nunca } \\
\text { Algunas veces } \\
\text { Frecuentemente } \\
31,4 \%\end{array}$ & $\begin{array}{l}\text { Se observa que el } 86.5 \% \text { de las personas en el rango } \\
\text { de siempre a algunas veces tuvo conflicto debido a } \\
\text { tener que resolver varias actividades al mismo } \\
\text { tiempo, misma consideración que coincide en la } \\
\text { gráfica 4, reforzando la percepción de disminución } \\
\text { de calidad de vida de sus habitantes, en } \\
\text { concordancia con el estudio expuesto por Damián } \\
\text { (2005). }\end{array}$ \\
\hline
\end{tabular}

Fuente: Elaboración propia.

ACE, 16 (46) CC BY-ND 3.0 ES | UPC Barcelona, España | Percepción de la calidad de vida en la vivienda. Periodo de contingencia por COVID-19 en la ciudad de Xalapa-México. DOI: http://dx.doi.org/10.5821/ace.16.46.9492 
En la Tabla 4 se detallan los resultados relacionados con las preguntas referentes a la valoración de la vivienda, desde la perspectiva del habitante a partir de las necesidades originadas por el confinamiento.

Tabla 4. Valoración de la vivienda

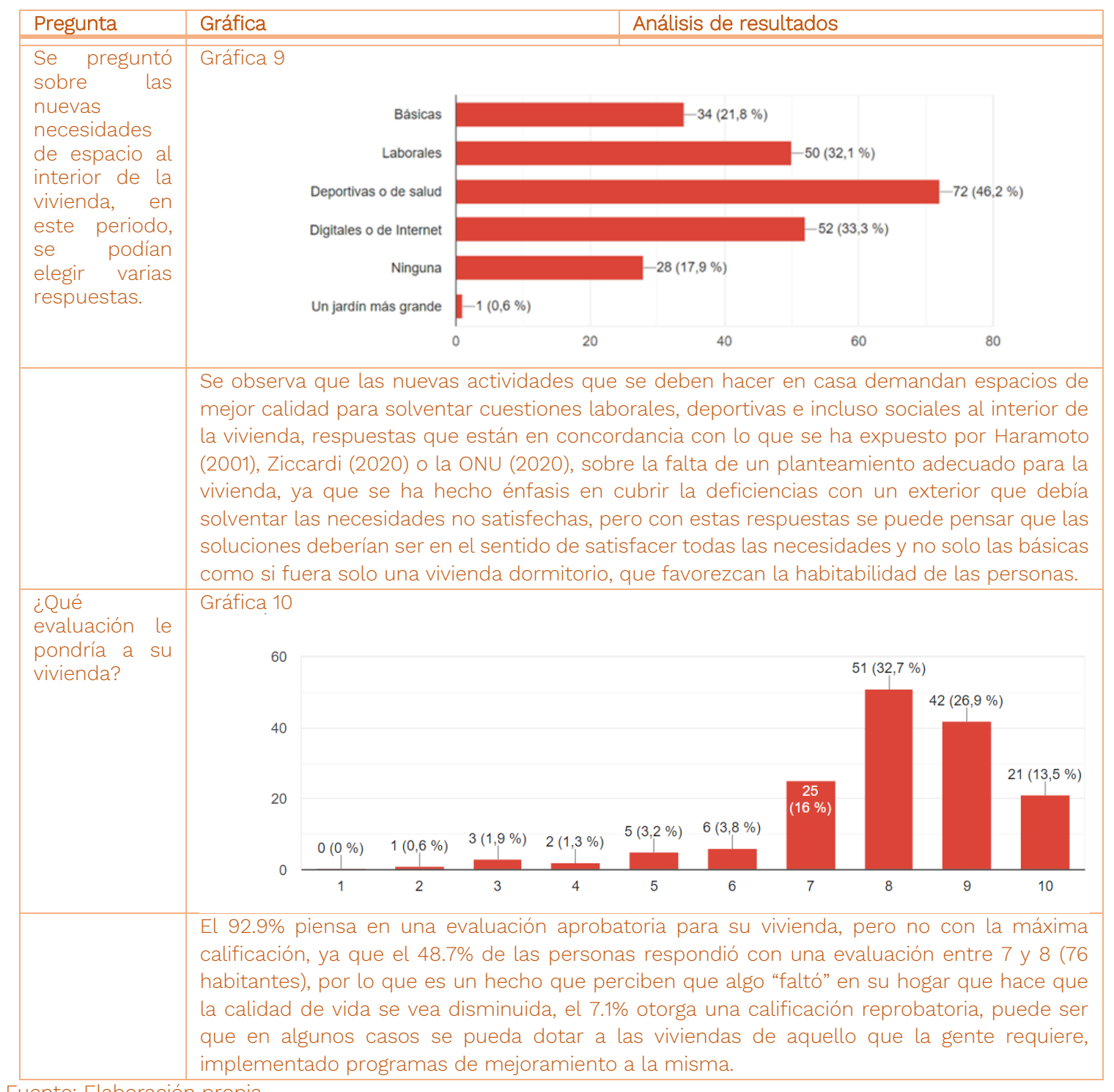

Fuente: Elaboración propia.

Se tuvo la oportunidad de entrevistar a varias personas, por videoconferencia, después de la encuesta realizada y pudieron externar los siguientes comentarios que expresan con mayor profundidad la situación por la cual están pasando, beneficios y conflictos derivados del encierro, así como la percepción de la respuesta de su vivienda a las actividades necesarias de realizar ante esta contingencia, ya que los testimonios reflejan el cómo lo cotidiano se transformó en un cruce de actividades que alteró el orden al que cada familia estaba acostumbrado. Se logró recolectar una muestra de 20 testimonios y se colocan en este documento solo 5 debido a la gran coincidencia en sus declaraciones.

ACE, 16 (46) CC BY-ND 3.0 ES | UPC Barcelona, España | Percepción de la calidad de vida en la vivienda. Periodo de contingencia por COVID-19 en la ciudad de Xalapa-México. DOI: http://dx.doi.org/10.5821/ace.16.46.9492 
Testimonios:

En un principio me fue difícil tomar control sobre la situación, creo que a todos nos llegó a pasar, pues no esperábamos una situación como esta. La fortuna de tener profesores con disposición y tener medios digitales, me dio la oportunidad de continuar con mis estudios. Las dificultades que se me presentaron, fue la organización en casa, ya que, con anterioridad, llevaba una rutina, en casa somos 3, mi pareja, mi hijo de 2 años y yo, y las actividades académicas y laborales estaban organizadas, de tal manera que trabajábamos sin interrupción, posteriormente en la tarde nos reuníamos para la convivencia familiar. La situación actual al estar todos en un mismo lugar, nos llevó a una desorganización y cambio de hábitos, vivimos en una casa pequeña, que en tiempo normal podemos realizar lo que nos corresponde, pero actualmente en el tiempo de trabajo, se producen ruidos, nuestro hijo al vernos en casa, desea estar con uno porque considera que existe la posibilidad de jugar todo el tiempo. En un principio, pensé que iba a contar con el tiempo para realizar mi trabajo y mis actividades académicas, con el paso de los días, se volvía más difícil cumplir y me fue haciendo sentir mal, aunque existió flexibilidad por parte de mis profesores, el estrés y la depresión empezaron a afectarme, trataba de buscar una motivación, pero también me ocasionó problemas con las relaciones en casa. La situación de estar en casa, con la responsabilidad de una familia, requiere disciplina, es posible avanzar con organización, pero la presencia de la familia te atrae, en consecuencia, viene la distracción. Aprendí a ser tolerante y más organizado.

Hombre 32 años.

Es una situación que cambió el panorama de cómo realizábamos las actividades cotidianas, de manera personal, me ha causado agobio, estrés, discontinuidad, aparentemente una nueva clase de depresión, ya que estaba acostumbrado a una dinámica diferente de movilidad, creo que debemos replantearnos como vamos a actuar. En mi caso particular, me ha afectado en los horarios, los horarios de sueño a veces son cortos o largos, igual los horarios de trabajo son difíciles, el horario de trabajo se junta con las actividades de casa.

Tengo una casa con jardín, me permite tener movilidad, no existe conflicto de espacio, pero aun así no me permite concentrarme para realizar mis actividades porque la familia es un distractor importante, pienso que uno debe ser creativo para encontrar el momento del día para realizar las actividades, para poder concentrarme, sucede que durante el día no me concentro y durante la noche fluye mejor mi trabajo, ya que no me distraigo con todo, por lo que puedo percibir lo que sucede en el hogar durante el día. La movilidad está recortada, pero no es estricta como en otras familias, se sale por cuestiones necesarias o por cuestiones laborales.

Hombre 30 años.

Cuando inició la cuarentena siempre tuve una actitud positiva, pensé que iba a tener tiempo para terminar mis materias, para realizar la tesis, pero no fue así, las cosas no fueron tan fáciles, no había acceso a la biblioteca para libros que necesitaba, las clases en línea no permitían conciliar, tan fácilmente, los tiempos de casa y los tiempos de clase, y todos los distractores que fueron agregándose.

En mi casa somos 4 personas, las cuales los 4 si estamos cumpliendo la cuarentena, contamos con internet y con equipo de 2 computadoras; antes de la pandemia, no había problema porque se tenía organizado el tiempo de trabajo, el tiempo de escuela, ahora, todas las actividades laborales de mis padres y académicas mías y de mi hermana se ven afectadas por que son los mismos tiempos, lo cual o deberíamos tener más equipo o debemos ser muy cuidadosos con la organización para afectarnos lo menos posible.

He tenido ansiedad por el encierro y estrés por que no puedo concluir mis trabajos según lo programado, no he podido hacer el ejercicio al que estaba acostumbrada.

ACE, 16 (46) CC BY-ND 3.0 ES | UPC Barcelona, España | Percepción de la calidad de vida en la vivienda. Periodo 15 de contingencia por COVID-19 en la ciudad de Xalapa-México. DOI: http://dx.doi.org/10.5821/ace.16.46.9492 
Toda mi familia está respetando el aislamiento, mis padres por su edad pertenecen al grupo de más riesgo, por lo que he salido en contadas ocasiones para surtir la despensa, ahí es donde más veo que el aislamiento afecta.

Mujer 22 años.

Para mí fue difícil porque cuando inició la cuarentena tuve que regresar a mi casa, yo no soy de Xalapa, en cuanto a conectividad no es buena en el lugar de donde soy, en cambio donde vivía en Xalapa si me permitía realizar mis actividades académicas en línea, pero, aún con esta situación pude establecer comunicación con todos mis profesores en línea y gracias a su flexibilidad pude sacar el semestre adelante cumpliendo con todas mis evaluaciones. Trabajar desde casa ha sido complicado porque, al estar con mi familia, el ritmo de trabajo baja y la dinámica familiar te envuelve.

Hombre 22 años.

Yo extraño a Demetrio y Andrés y a todos mis amigos. Me he sentido triste en este tiempo. Me gustaría correr, me gustaría ir al centro comercial, comprar un helado, ver películas, quiero jugar en el parque para jugar futbol, quiero ir a la playa y hacer un castillo de arena, jugar con la pelota. Si me gusta mi casa, pero no puedo salir, extraño a mis amigos, extraño a la maestra y a mis abuelos, el coronavirus es muy molesto como el polvo y fastidia a toda la gente. En la escuela hay un árbol y lo extraño.

Niño 4 años.

\section{Conclusiones}

Iniciamos definiendo que la pretensión de este documento es repensar la formulación de propuestas para la producción de un hábitat saludable, adecuado, equitativo y sustentable, que impulse la generación de ideas en las que converjan enfoques multidisciplinarios, multisectoriales y multiactorales, fundamentados desde la diversidad que refleja nuestra realidad, con la oportunidad de que esto nos daría una contrastación entre la construcción teórica académica y la evaluación empírica pragmática.

Comprender la envergadura del planteamiento sistémico en el que se fundamenta y la complejidad e integralidad que se necesita para abordar la solución a los problemas que la realidad nos requiere resulta primordial. El Antropoceno nos enfrenta a circunstancias no precisamente nuevas, pero si sumamente complejas en la que las capacidades de colaboración deben ser el fin principal y en el que la demostración de los valores individuales y grupales deben dar pie a la conjunción de ideas para propuestas eficaces y efectivas.

En primera instancia es necesaria la articulación de los saberes desarrollados por la comunidad académica universitaria, las autoridades gubernamentales en sus diferentes niveles de gobierno, de empresarios, de grupos de Organizaciones No Gubernamentales o asociaciones civiles sin fines de lucro, hasta la participación de ciudadanos con conocimiento sobre las vivencias de estos problemas, por la cotidianeidad con la que lidian con ellos, para la visualización de alternativas que busquen resolver los problemas actuales en el hábitat residencial.

Es ahora, más que nunca, que los problemas en el hábitat para la obtención de condiciones de sostenibilidad deben de plantearse desde la búsqueda del equilibrio con la naturaleza, la articulación con el suelo, la vivienda, los servicios básicos de infraestructura para su dotación, la movilidad, los

ACE, 16 (46) CC BY-ND 3.0 ES | UPC Barcelona, España | Percepción de la calidad de vida en la vivienda. Periodo de contingencia por COVID-19 en la ciudad de Xalapa-México. DOI: http://dx.doi.org/10.5821/ace.16.46.9492 
equipamientos, la accesibilidad, la asequibilidad, el financiamiento, desde un sistema dinámico de manifestación cultural, que define su identidad y simbolismo, en evolución con el paso del tiempo.

La protección plena a los derechos vinculantes e indivisibles del habitante, que permitan definir el desarrollo de los procesos de producción y gestión de la vivienda, como un sistema que se articule desde factores cuantitativos y cualitativos, que permita la satisfacción integral de necesidades y motivaciones, con identificación de la idiosincrasia y cultura del habitante, vinculada a actividades o funciones con sanidad, en un hábitat en condiciones de bienestar.

Al concebir como recurrentes estas circunstancias que ahora se están viviendo, resulta obligatorio repensar las formas en las que se definen las estrategias o las acciones que deriven en mejores condiciones de vida y de bienestar para todos, que conciban los procesos de consolidación desde factores que se adquieren con el tiempo, por lo que es necesario establecer entornos que permitan llevar a los polígonos habitacionales realmente a su fortalecimiento como espacios de vida saludables, equitativos, justos y armónicos con la naturaleza. Estas se deben de plantear desde la diversidad geográfica, social, económica y ambiental, para la formulación integral de un sistema habitacional adecuado, equitativo, saludable y sustentable, desvinculado de la lógica del capital y definida para la producción de la vida y permanencia de todos los seres, de relación humana con los ecosistemas, que reconcilie el espacio mental, el espacio real, físico y social en el que se habita.

El balance se encuentra, como plantea Breilh (2010), en estimular las relaciones social-biológicas y de sociedad-naturaleza, para no perder su existencia, en donde el habitante y la colectividad encuentren los adecuados modos de vivir, en estricto equilibrio entre el desarrollo natural y la existencia de la vida humana, asegurando su bienestar, así como el equilibrio con el medioambiente urbano.

Este equilibrio puede permitir la creación del sistema habitacional a aquel en donde sus habitantes, su familia y su colectividad encuentren adecuadas condiciones de habitabilidad, desde los procesos fisiológicos, de soportes y de defensas físicas, en mejores condiciones psicológicas o fisiopatológicas para el desarrollo humano, en relación con su entorno y con un estado de bienestar colectivo.

Se ha encontrado que los grupos sociales han tenido doble aislamiento según los testimonios, al no existir posibilidad para un espacio público o colectivo al interior de la vivienda, el aislamiento que generó estrés, ansiedad y la falta de cumplimiento con el trabajo excesivo. Por lo que se ha evidenciado la importancia de la ubicación de la vivienda, se debe replantear la visión desde el impulso al desarrollo de esta y pensar realmente en que la vivienda no es un contenedor, sino realmente un espacio habitable que le ofrece vida y formación a sus habitantes y no por el contrario que sea en detrimento de su bienestar. Al consultar a la población queda claro que el espacio público pasa a segundo término, se piensa más en espacios que permitan el desarrollo de todas las actividades, desde la flexibilidad del hogar, por lo que se requiere plantear una vivienda dinámica, que sea resguardo para el descanso, la reproducción, el ocio, pero también como espacio deportivo, laboral, educativo, de salud en vínculo con su ecosistema, de satisfacción 24 horas diarias y siete días de la semana. Esto lleva a un nuevo desafío en cuanto a las políticas públicas, ya que se requiere la producción de una vivienda nueva y de mejoramiento adecuada a nuestras circunstancias, no solo desde el enfoque de sus consideraciones técnicas, sino de rehabilitación de un hábitat en el que se inserta el ser humano y desde el que debe de reproducir la vida.

Dicha estrategia debe evitar la expansión urbana y conciliar varios factores, una ciudad más verde, menos densa, una periferia más equilibrada y equitativa, con lugares de convivencia y producción, al prevalecer la habitabilidad desde la diversidad, que encuentre en el espacio interior bienestar y no

ACE, 16 (46) CC BY-ND 3.0 ES | UPC Barcelona, España | Percepción de la calidad de vida en la vivienda. Periodo de contingencia por COVID-19 en la ciudad de Xalapa-México. DOI: http://dx.doi.org/10.5821/ace.16.46.9492 
insatisfacción, en espacios pluri-funcionales tanto en lo público como en lo privado en concordancia con Ziccardi (2020).

"La vivienda es la manifestación física del espacio requerido por el hombre para vivir junto con su familia" (Sepúlveda, 1986. p. 14), es una premisa que la pandemia dejó en claro y se ve con más crudeza lo que ha manifestado desde hace años, que se requería que no solo se pudieran satisfacer las necesidades básicas del habitante, sino que permitiera realizar las actividades requeridas por el usuario con holgura, que permita también tener condiciones de higiene, dependiendo de la cultura del usuario, con el tiempo necesario para trabajar, entretenerse y descansar como lo señala Damián (2005).

Esta etapa de confinamiento ha visibilizado la inseguridad en la vivienda, ya que las condiciones internas han resaltado situaciones de violencia, inseguridad, estrés o afectaciones psicológicas que post pandemia se estarán haciendo evidentes en todos los grupos etarios y requerirán de darles solución, pero también se demuestra la precarización de los entornos en los que habitamos, la falta de habitabilidad y de condiciones de bienestar como hace referencia Ezquiaga (2020).

El habitante percibe la calidad de vida según sus costumbres, su cultura, de una forma personal (Sepúlveda, 1986), pero la situación actual revela que, al modificar las condiciones de realización de las actividades cotidianas, se han alterado las costumbres y la forma particular de cada individuo de convivir con su familia, por lo que resulta evidente la urgencia de reformular la vivienda adecuándola nuestras condiciones actuales.

\section{Autoría}

La primera autora ha conceptualizado, diseñado y escrito la investigación; el segundo autor ha asesorado la investigación y contribuido en la realización del estudio desde la perspectiva del hábitat residencial, así como la revisión del manuscrito para su publicación como artículo científico.

Conflicto de intereses: Los autores declaran que no hay conflicto de intereses.

\section{Bibliografía}

Anderson, J. (2004). Calm investigation of the circumstance that have led to the present scarcity of grain in Britain. En Foster J.B. La ecología de Marxs: Materialismo y naturaleza. Barcelona: Ediciones El Viejo Topo.

Baldi, G. y García E. (2005) Calidad de vida y medio ambiente. La psicología ambiental. Universidades, (30) 9-16.

Bachelard, G. (2000). La formación del espiritu científico. Contribución a un psicoanálisis de conocimiento objetivo. 23 edición. México: Siglo XXI.

Breilh, J. (2010), La epidemiología crítica: una nueva forma de mirar la salud en el espacio urbano. Salud Colectiva, 6(1), 83-101, enero-abril.

Biere Arenas, R. (2021) Ciudad y Territorio Virtual. 2004-2019, Barcelona 15 años después. ACE: Architecture, City and Environment, 15(45), 10380. DOI: http://dx.doi.org/10.5821/ace.15.45.10380

ACE, 16 (46) CC BY-ND 3.0 ES | UPC Barcelona, España | Percepción de la calidad de vida en la vivienda. Periodo 18 de contingencia por COVID-19 en la ciudad de Xalapa-México. DOI: http://dx.doi.org/10.5821/ace.16.46.9492 
Boltvinik, J. (22 de mayo 2020). Dos importantes ensayos para entender y pensar la pandemia..., y lo que sigue. Economía Moral, La jornada. Recuperado de https://www.jornada.com.mx/2020/05/22/opinion/02601eco

Damián, A. (2005). La pobreza de tiempo: el caso de México. Estudios sociológicos de El Colegio de México. 23 (69), 807-843, septiembre-diciembre.

Ezquiaga Domínguez, J. N. (2020). Hay que Defender la Ciudad: De la Distopía a la Ciudad Abierta. ACE: Architecture, City and Environment, 15(43), 9518. DOI: http://dx.doi.org/10.5821/ace.15.43.9518

Gobierno de México (2020). Quédate en Casa. Recuperado de https://coronavirus.gob.mx/quedate$\underline{\text { en-casa/\# }}$

González, F. (2004). Lugarización, globalización y gestión local. Polis Revista Latinoamericana. 7(2004), 1-15. Recuperado de https://journals.openedition.org/polis/6222\#quotation

Haramoto, E. (2001). Vivienda Social una hipótesis de acción. Revista INVI, 16(44), 49-64. Recuperado de https://revistainvi.uchile.cl/index.php/INVI/article/view/62248/66372

Jirón et al, (2004). Bienestar Habitacional. Guía de diseño para un hábitat residencial sustentable. Santiago, Chile. Ed. Universidad de Chile, Instituto de Vivienda.

Lefebvre, H. (2001). The production of space. Oxford \& Cambridge, UK: Blackell.

INEGI. (2018). Delimitación de las zonas metropolitanas de México 2015. SEDATU. Recuperado de https://www.inegi.org.mx/contenido/productos/prod_serv/contenidos/espanol/bvinegi/productos/nu eva estruc/702825006792.pdf

INEGI. (2020). Comunicado de prensa № 24/21. Recuperado de https://www.inegi.org.mx/contenidos/saladeprensa/boletines/2021/EstSociodemo/ResultCenso2020 Nal.pdf

Iracheta, A. (2020). La ciudad que quisiéramos después de COVID-19. ACE: Architecture, City and Environment, 15(43), 9512. DOI: http://dx.doi.org/10.5821/ace.15.43.9512

Issberner, L. y Léner, P. (2018). Antropoceno: la problemática vital de un debate científico. Correo de la UNESCO. 18-2. Recuperado de https://es.unesco.org/courier/2018-2/antropoceno-problematicavital-debate-cientifico

Nussbaum, M. y Sen, A. (1998). La calidad de vida. México: Fondo de Cultura Económica.

ONU-Hábitat. (2018). La vivienda en el centro de los ODS en México. Seis orientaciones estratégicas. Programa de las Naciones Unidas para los Asentamientos Humanos, ONU-Hábitat. México.

ONU. (2020). La pandemia de coronavirus es una oportunidad para construir una economía que preserve la salud del planeta. Noticias ONU. Recuperado de https://news.un.org/es/story/2020/04/1472482

Romero G. (2020). La UNAM responde, informe de habitabilidad de viviendas y el entorno urbano ante el COVID19. Recuperado de https://tv.unam.mx/portfolio-item/la-unam-responde-informe-dehabitabilidad-de-viviendas-y-el-entorno-urbano-ante-el-covid19/

ACE, 16 (4.6) CC BY-ND 3.0 ES | UPC Barcelona, España | Percepción de la calidad de vida en la vivienda. Periodo 19 de contingencia por COVID-19 en la ciudad de Xalapa-México. DOI: http://dx.doi.org/10.5821/ace.16.46.9492 
Sepúlveda, O. (1986). El espacio en la vivienda social y calidad de vida. Revista INVI, 1(2), 10-34. Recuperado de https://revistainvi.uchile.cl/index.php/INVI/article/view/61937/66028

Sepúlveda, R. et al. (1999). Seguridad residencial y comunidad. Santiago, Chile. Ed. Universidad de Chile, Instituto de Vivienda. Recuperado de http://libros.uchile.cl/494

Sigüenza, C. y Rebollo, E. (2020). Byung-Chul Han: Viviremos como en un estado de guerra permanente. La Vanguardia. España. Recuperado de https://www.lavanguardia.com/cultura/20200512/481122883308/byung-chul-han-viviremos-comoen-un-estado-de-guerra-permanente.html

Spinney, L. (2020). Will coronavirus lead to fairer societies? Thomas Piketty explores the prospect. The Guardian. Recuperado de https://www.theguardian.com/world/2020/may/12/will-coronavirus-leadto-fairer-societies-thomas-piketty-explores-the-prospect

Vargas J. (2020). Cinco personas, 35 metros cuadrados y cinco semanas de confinamiento. Público España. Recuperado de https://www.publico.es/sociedad/confinamiento-viviendas-pequenas-cincopersonas-35-metros-cuadrados-cinco-semanas-confinamiento.html

Ziccardi, A. (2020). Ciudades en revisión, Ciudades reimaginadas. Barcelona, México, Buenos Aires, París ante la crisis. Recuperado de https://www.youtube.com/watch?v=6mFOHCp9zONGK7XgQWLpSwSvuo 